\title{
Prevalence and correlates of highly caffeinated beverage consumption among Korean adolescents
}

\section{Ho-Kyung Kwak $^{1}{ }^{\oplus}$, Jaesin $\mathrm{Sa}^{2}{ }^{\oplus}$, Siyoung Choe ${ }^{3}{ }^{\oplus}$, Jean-Philippe Chaput ${ }^{4}{ }^{\oplus}$, Joon Chung ${ }^{5}$, Gayle Cummings ${ }^{6}{ }^{(}{ }^{\text {, Jounghee }}$ Lee $^{7}$ (1)}

${ }^{1}$ Division of Human Ecology, Korea National Open University, Seoul, Korea

${ }^{2}$ Department of Health and Human Performance, University of Tennessee at Chattanooga, Chattanooga, TN, USA

${ }^{3}$ Department of Kinesiology and Health, Miami University, Oxford, OH, USA

${ }^{4}$ Department of Pediatrics, University of Ottawa, Ottawa, ON, Canada

${ }^{5}$ Department of Medicine, Harvard Medical School, Boston, MA, USA

${ }^{6}$ College of Education and Health Sciences, Touro University, Vallejo, CA, USA

${ }^{7}$ Department of Food and Nutrition, Kunsan National University, Gunsan, Korea

Received: January 13, 2021

Revised: May 26, 2021

Accepted: October 31, 2021

Corresponding author: Jounghee Lee

Department of Food and

Nutrition, Kunsan National

University, 558 Daehak-ro,

Gunsan 54150, Korea

E-mail: joungheelee@kunsan.ac.kr

\section{ABSTRACT}

Objectives: The purposes of this study were to (1) examine the multi-year prevalence of highly caffeinated beverage ( $\mathrm{HCB}$ ) consumption, (2) identify sex differences in the prevalence, and (3) investigate relationships between HCB consumption and behavioral characteristics in a nationally representative sample of Korean adolescents.

Methods: Data from the Korea Youth Risk Behavior Web-based Survey (2014-2017) were analyzed. Results: HCB consumption was higher in 2017 than 2014 (23.9\% vs. 12.0\%), and higher among boys than girls (17.2\% vs. 13.1\%). HCB drinkers were more likely to (1) be boys, (2) be overweight or obese, (3) use alcohol and tobacco, (4) consume soda at least once per week, (5) consume sweetened beverages at least once per week, (6) have seriously considered suicide during the past 12 months, and (7) have attempted suicide during the past 12 months ( $p<0.05$ for all).

Conclusion: Effective programs to curb HCB consumption among Korean adolescents need to be established.

Keywords: Adolescent; Behavior; Beverages; Caffeine

\section{Introduction}

The consumption of highly caffeinated beverages (HCBs), often referred to as "energy drinks," is an issue of growing concern [1]. Although HCBs are advertised as providing various benefits, such as improved energy and performance, they may cause respiratory disorders, seizures, and insomnia [2]. Despite these health risks, caffeine is one of the most widely used psychoactive substances in the world [3], including in South Korea (hereafter, Korea) [4,5]. Caffeine consumption 
has steadily grown in Korea [4,5]. The majority of HCBs available today first entered the Korean market in 2010 [4,5], and according to a 2013 estimate, HCBs have since grown to an industry worth approximately 90 million United States dollars (USD) [5]. One study found that Koreans consume an estimated 67.8 to $102.6 \mathrm{mg}$ of caffeine per day from all food sources [6], but that study used data from before HCBs became popular in Korea. The prevalence of coffee consumption was reported to be $52.3 \%$ [7], but the prevalence of HCB consumption remains unclear despite these products' popularity in Korea.

Adolescents are vulnerable to HCB abuse, as HCBs are readily accessible, relatively inexpensive, and have a sweet flavor that is more appealing to younger consumers than coffee $[1,8]$. Adolescents who consume HCBs may be at higher risk of caffeine intoxication than adults [9]. Korean adolescents may be particularly vulnerable to $\mathrm{HCB}$ abuse and caffeine intoxication, as many rely on HCBs to stay awake or focus on studying [10]. The Korean government attempted to limit adolescents' caffeine intake by restricting advertisements, requiring warning labels, and banning the sale of HCBs on school grounds [11]. However, the effectiveness of those policies remains unclear, as no studies to date have examined changes in Korean adolescents' HCB consumption over multiple years.

Past studies [12,13] found that Korean adolescents who consumed HCBs were at greater risk of stress, anxiety, and depression. Unlike the psychological health problems associated with $\mathrm{HCB}$ consumption, relatively little attention has been given thus far to the relationship between $\mathrm{HCB}$ consumption and behavioral factors (e.g., physical activity, sleep, suicidal behavior, and alcohol and tabaco use). Furthermore, the data on sex differences in the multi-year prevalence of $\mathrm{HCB}$ consumption are sparse, and little is known about the multi-year prevalence of HCB consumption among Korean adolescents. The purposes of this study were to (1) examine the multi-year prevalence of HCB consumption from 2014 to 2017, (2) identify, if any, sex differences in the multiyear prevalence, and (3) investigate relationships between $\mathrm{HCB}$ consumption and behavioral characteristics using a nationally representative sample of Korean adolescents.

\section{Materials and Methods}

\section{Survey and Participants}

Since 2005 the Korea Youth Risk Behavior Web-based Survey (KYRBS) has been conducted by the Korea Centers for Disease Control and Prevention (now known as the Korea Disease Control and Prevention Agency) every year. Because the KYRBS has collected HCB-related information since 2014, we combined 4 data sets of KYRBS from 2014 to 2017. The KYRBS uses a self-administered questionnaire and 2-stage sampling. In the first stage, each school (including middle and high schools) was selected as a primary sampling unit (PSU). In the second stage, a classroom of each grade was chosen within a PSU using the systematic sampling method. The probability of selection was $14 \%$ of total middle and high schools and $2 \%$ of total students [14]. The KYRBS team obtained online consent from all participants. This research received Institutional Review Board approval from Touro University (IRB No: PH0219).

This data set includes a representative sample of middle and high school students in Korea $(n=267,907)$ from the following years: (1) 2014 ( $n=72,060$; 97.2\% response rate); (2) 2015 ( $n=68,043$; 96.7\% response rate); (3) 2016 ( $n=65,528$; 96.4\% response rate); and (4) 2017 ( $n=62,276 ; 95.8 \%$ response rate) [14]. The exclusion criteria were (1) students needing special education services or (2) students with reading difficulties.

\section{Independent Variables}

The school level of participants was grouped into middle and high school. Students responded to academic achievement with 5 options, and we combined these options into 3 responses: (1) low (i.e., low or middle-low), (2) middle, and (3) high (i.e., high or middle-high) [15]. The household income of each student was provided using 5 options, which we combined into 3 levels: (1) low (i.e., very low or low), (2) middle, and (3) high (i.e., very high or high) [15].

Participants provided information on their weekly expenditures with 6 options, from $0 \leq 10,000$ Korean won (KRW) (equivalent to $0 \leq$ USD 8.92) to $\geq 150,000 \mathrm{KRW}$ (USD 133.80) and regrouped into 3 levels: (1) <50,000 KRW (equivalent to <USD 44.66), (2) 50,000 to 99,999 KRW (USD 44.66-89.32), and (3) $\geq 100,000 \mathrm{KRW}$ ( $\geq$ USD 89.33). The education level of their parents was divided into 3 groups: $\leq$ middle school; high school; and $\geq$ college.

Self-reported weight and height were used for the assessment of body mass index (BMI), which was calculated as weight in kilograms divided by height in meters squared. We used the 2017 Korean National Growth Chart sex-specific BMI-forage percentile cutoffs. The nutritional status of participants were grouped into 4 levels: (1) underweight (BMI < 5th percentile), (2) normal weight (5th $\leq \mathrm{BMI}<85$ th percentile), (3) overweight (85th $\leq \mathrm{BMI}<95$ th percentile), and (4) obese (BMI $\geq 95$ th percentile) [16].

Weekly exercise for $\geq 60$ minutes was originally answered with 8 options from 0 to 7 days for the last 7 days. We regrouped these responses into 3 categories: (1) none, (2) 1 to 2 days, and (3) $\geq 3$ days [15]. The responses for weekly vigorous exercise 
for $\geq 20$ minutes were originally categorized into 6 groups. We recoded them into 3 levels: (1) none, (2) 1 to 2 days, and (3) $\geq 3$ days. Tobacco use of participants during their lifetime was dichotomized as "never" versus "ever."

The National Sleep Foundation recommends that adolescents sleep for 8 to 10 hours per night [17]. We dichotomized participants as meeting or not meeting this recommendation. Participants described whether they felt fatigue relief after sleep with 5 options, from "not enough at all" to "more than enough." We recoded these responses into 3 groups: (1) "not enough/not enough at all," (2) "fair," and (3) "more than enough/enough." The following information of participants was dichotomized as "no" or "yes": (1) having seriously considered suicide during the last year and (2) having attempted suicide during the last year.

Alcohol use of participants during their lifetime was assessed to compare users with nonusers. Weekly intake frequency of soda and sweetened beverages (excluding soda and HCBs) was categorized into 7 options, from never to $\geq 3$ times per day for the last 7 days. We recoded them into 3 groups: (1) 0 times, (2) 1 to 2 times, and (3) $\geq 3$ times per week.

\section{Dependent Variable}

Information on HCB consumption was elicited by the following question, "During the past 7 days, how frequently did you drink highly caffeinated beverages?" with 7 levels: (1) never, (2) 1 to 2 times per week, (3) 3 to 4 times per week, (4) 5 to 6 times per week, (5) 1 time per day, (6) 2 times per day, and (7) 3 times or more per day. Using these responses, we dichotomized participants into HCB drinkers and HCB nondrinkers.

\section{Statistical Analysis}

We implemented the Cramer V test to examine the statistical significance of differences in behavioral characteristics between HCB drinkers and nondrinkers. We calculated the prevalence of HCB intake from 2014 to 2017 with 95\% confidence intervals. Graphical plots were created by survey year and sex. We performed multiple logistic regression to examine behavioral factors associated with HCB intake with adjustment for school year, household income of family level, weekly expenditure, and academic achievement based on previous studies [18-20]. We conducted a complete case analysis except all records with any missing information on the variables of our interest. We used STATA ver. 14 (STATA Press, College Station, TX, USA) for statistical analyses, and took the sample weights into consideration by using the svy command for the complex survey design.

\section{Results}

The final data set included 267,907 middle and high school students. Their mean age was 15.0 years (standard deviation, 1.7 years) and $51.2 \%$ of them were boys. Among the male participants, $17.2 \%$ were HCB drinkers (Table 1). Merely 24.1\% of male participants met the daily recommendation of 8 to 10 hour sleep duration. Male participants had the highest proportion of normal weight (72.7\%), followed by obesity (10.2\%), overweight (8.7\%), and underweight (8.4\%). Negligible associations were found between HCB consumption and the independent variables. However, HCB consumption was weakly associated with soda intake (Cramer $\mathrm{V}=0.190)$ and sweetened beverage intake (Cramer V $=0.155$ ) (Table 1).

Among female participants, only 13.1\% were HCB drinkers (Table 2). The majority of female participants (87.3\%) did not meet the daily recommendation of sleep duration (8 to 10 hours per night). More than three-fourths of female participants were in the normal weight category (78.8\%), followed by overweight (8.5\%), obesity (6.4\%), and underweight (6.3\%). The magnitude of the associations between HCB consumption and the independent variables was negligible. However, there were weak associations between HCB consumption and soda consumption (Cramer V $=0.148$ ) and sweetened beverage consumption (Cramer V $=0.144$ ) (Table 2).

Among the total participants, the prevalence of $\mathrm{HCB}$ consumption was 1.8\%p higher in 2016 (13.8\%) than in 2014 (12.0\%) (Figure 1). The prevalence increased by 10.1\%p between 2016 (13.8\%) and 2017 (23.9\%). This gap was considerably higher for male participants (11.7\%p compared with female participants ( $8.5 \% \mathrm{p})$ in this short time period. In 2017, HCB consumption was more prevalent in male participants (26.7\%) than in female participants (20.9\%).

In the overall sample, higher odds of HCB consumption were related to male sex, overweight or obesity, alcohol consumption, and tobacco use ( $p<0.05$ for all) (Table 3 ). Moreover, HCB consumption showed significantly relationships with (1) $>60$ minutes of physical activity 1 to 2 days per week, (2) $>1$ time per week of soda consumption, (3) $>1$ time per week of sweetened baverage consumption ( $p<0.05$ for all), (4) feeling less than enough fatigue relief after sleep, (5) having seriously considered suicide during the last 12 months, and (6) having attempted suicide during the last 12 months $(p<0.05$ for all). Lower odds of HCB consumption were associated with high school maternal education level and underweight ( $p<0.05$ for both).

Among male participants, HCB drinkers were more likely to be obese, drink alcohol, and use tobacco ( $p<0.05$ for all). Additionally, higher odds of HCB consumption were associated with (1) $\geq 60$ minutes of physical activity 1 to 2 days per week, 
Table 1. Characteristics of boys by highly caffeinated beverage consumption, Korea Youth Risk Behavior Web-based Survey 2014-2017

\begin{tabular}{|c|c|c|c|c|c|}
\hline Characteristic & $\begin{array}{c}\text { Total } \\
(n=137,101) \\
(\%)\end{array}$ & $\begin{array}{c}\text { Drinker } \\
(n=23,600) \\
(\%)\end{array}$ & $\begin{array}{c}\text { Nondrinker } \\
(n=113,501) \\
(\%)\end{array}$ & $\begin{array}{l}\text { Effect } \\
\text { size }\end{array}$ & $p$ \\
\hline \multicolumn{6}{|l|}{ School type } \\
\hline Middle school & 46.6 & 43.8 & 47.2 & 0.026 & $<0.001$ \\
\hline High school & 53.4 & 56.2 & 52.8 & & \\
\hline \multicolumn{6}{|l|}{ Academic achievement } \\
\hline Low & 34.0 & 38.6 & 33.1 & 0.045 & $<0.001$ \\
\hline Middle & 27.3 & 26.2 & 27.5 & & \\
\hline High & 38.7 & 35.2 & 39.5 & & \\
\hline \multicolumn{6}{|l|}{ Household income } \\
\hline Low & 16.0 & 17.3 & 15.7 & 0.026 & $<0.001$ \\
\hline Middle & 44.6 & 41.9 & 45.2 & & \\
\hline High & 39.4 & 40.9 & 39.1 & & \\
\hline \multicolumn{6}{|l|}{ Weekly expenditure } \\
\hline$<50,000 \mathrm{KRW}(<$ USD 44.66) & 85.1 & 78.8 & 86.4 & 0.087 & $<0.001$ \\
\hline 50,000-99,999 KRW (USD 44.66-89.32) & 9.8 & 12.7 & 9.2 & & \\
\hline$\geq 100,000 \mathrm{KRW}(\geq$ USD 89.33) & 5.1 & 8.5 & 4.4 & & \\
\hline \multicolumn{6}{|l|}{ Paternal education } \\
\hline$\leq$ Middle school & 3.0 & 3.4 & 2.9 & 0.013 & 0.001 \\
\hline High school & 33.4 & 32.4 & 33.6 & & \\
\hline$\geq$ College & 63.7 & 64.2 & 63.5 & & \\
\hline \multicolumn{6}{|l|}{ Maternal education } \\
\hline$\leq$ Middle school & 2.4 & 2.7 & 2.3 & 0.015 & $<0.001$ \\
\hline High school & 41.1 & 39.7 & 41.4 & & \\
\hline$\geq$ College & 56.5 & 57.6 & 56.3 & & \\
\hline \multicolumn{6}{|l|}{$\mathrm{BMI}^{\mathrm{b})}$} \\
\hline Underweight & 8.4 & 8.0 & 8.5 & 0.019 & $<0.001$ \\
\hline Normal weight & 72.7 & 72.1 & 72.8 & & \\
\hline Overweight & 8.7 & 8.8 & 8.6 & & \\
\hline Obese & 10.2 & 11,1 & 10.0 & & \\
\hline \multicolumn{6}{|l|}{ Alcohol use } \\
\hline Never & 54.4 & 45.9 & 56.1 & 0.077 & $<0.001$ \\
\hline Ever & 45.6 & 54.1 & 43.9 & & \\
\hline \multicolumn{6}{|l|}{ Tobacco use } \\
\hline Never & 75.9 & 68.7 & 77.4 & 0.076 & $<0.001$ \\
\hline Ever & 24.1 & 31.3 & 22.6 & & \\
\hline \multicolumn{6}{|l|}{ Weekly physical activity for $\geq 60 \mathrm{~min}$} \\
\hline None & 27.4 & 24.5 & 28.0 & 0.030 & $<0.001$ \\
\hline $1-2$ days & 30.1 & 31.6 & 29.8 & & \\
\hline$\geq 3$ days & 42.5 & 43.9 & 42.2 & & \\
\hline \multicolumn{6}{|l|}{ Weekly vigorous exercise for $\geq 20 \mathrm{~min}$} \\
\hline None & 14.0 & 12.5 & 14.3 & 0.021 & $<0.001$ \\
\hline $1-2$ days & 36.4 & 36.3 & 36.4 & & \\
\hline$\geq 3$ days & 49.6 & 51.2 & 49.3 & & \\
\hline \multicolumn{6}{|l|}{ Weekly frequency of soda consumption } \\
\hline 0 times & 18.4 & 8.3 & 20.5 & 0.190 & $<0.001$ \\
\hline $1-2$ times & 46.7 & 38.0 & 48.5 & & \\
\hline$\geq 3$ times & 34.9 & 53.8 & 31.0 & & \\
\hline
\end{tabular}


Table 1. Continued

\begin{tabular}{|c|c|c|c|c|c|}
\hline Characteristic & $\begin{array}{c}\text { Total } \\
(n=137,101) \\
(\%)\end{array}$ & $\begin{array}{c}\text { Drinker } \\
(n=23,600) \\
(\%)\end{array}$ & $\begin{array}{c}\text { Nondrinker } \\
(n=113,501) \\
(\%)\end{array}$ & $\begin{array}{l}\text { Effect } \\
\text { size }^{\text {a) }}\end{array}$ & $p$ \\
\hline \multicolumn{6}{|c|}{ Weekly frequency of sweetened beverage consumption } \\
\hline 0 times & 14.4 & 6.0 & 16.2 & 0.155 & $<0.001$ \\
\hline $1-2$ times & 40.8 & 33.7 & 42.3 & & \\
\hline$\geq 3$ times & 44.8 & 60.4 & 41.6 & & \\
\hline \multicolumn{6}{|c|}{ Meeting sleep duration recommendations (8-10 h) } \\
\hline Not met & 75.9 & 78.5 & 75.4 & 0.028 & $<0.001$ \\
\hline Met & 24.1 & 21.5 & 24.7 & & \\
\hline \multicolumn{6}{|l|}{ Feeling fatigue relief after sleep } \\
\hline Not enough/not enough at all & 34.8 & 40.8 & 33.5 & 0.060 & $<0.001$ \\
\hline Fair & 33.2 & 31.8 & 33.4 & & \\
\hline Very enough/enough & 32.1 & 27.5 & 33.1 & & \\
\hline \multicolumn{6}{|c|}{ Seriously considered suicide during last $12 \mathrm{mo}$} \\
\hline No & 90.1 & 85.3 & 91.1 & 0.073 & $<0.001$ \\
\hline Yes & 9.9 & 14.7 & 8.9 & & \\
\hline \multicolumn{6}{|l|}{ Suicide attempt during last $12 \mathrm{mo}$} \\
\hline No & 97.9 & 95.7 & 98.4 & 0.072 & $<0.001$ \\
\hline Yes & 2.1 & 4.3 & 1.6 & & \\
\hline
\end{tabular}

Use of weighted data with adjustment for the complex survey design. The percentages may not add to 100 because of rounding errors.

KRW, Korean won; USD, United States dollar; BMI, body mass index.

${ }^{\text {a) }}$ Phi effect sizes were considered negligible if $<0.1$, weak if between 0.1 and $<0.2$, moderate if between 0.2 and $<0.4$, and strong if $\geq 0.4$. ${ }^{\text {b) }}$ Underweight $(\mathrm{BMI}<5$ th percentile), normal weight (5th percentile $\leq \mathrm{BMI}<85$ th percentile), overweight (85th percentile $\leq \mathrm{BMI}<95$ th percentile), and obese $(\mathrm{BMI} \geq 95$ th percentile).

(2) $\geq 20$ minutes of vigorous exercise $\geq 3$ days per week, (3) $\geq 1$ time per week of soda consumption, (4) $>1$ time per week of sweetened beverage consumption, (5) not meeting the recommendation for an 8-10 hour sleep duration, (6) insufficient fatigue relief after sleep, (7) having seriously considered suicide during the last 12 months, and (8) having attempted suicide during the last 12 months $(p<0.05$ for all). Lower odds of HCB consumption were correlated with underweight ( $p<0.05$ for all).

Among female HCB drinkers, higher odds of HCB consumption were related to being obese, drinking alcohol, and using tobacco $(p<0.05$ for all). In girls, HCB consumption was correlated with (1) $>60$ minutes of physical activity 1 to 2 days per week, (2) >1 time per week of soda consumption, (3) >1 time per week of sweetened beverage consumption, (4) insufficient fatigue relief after sleep, (5) having seriously considered suicide during the last 12 months, and (6) having attempted suicide during the last 12 months ( $p<0.05$ for all). Lower odds of HCB consumption were correlated with high school maternal education $(p<0.05)$ (Table 3 ).

\section{Discussion}

The current study examined the multi-year prevalence of HCB consumption from 2014 to 2017 in a nationally representative sample of adolescents in Korea. This might be the only study to date to explore sex differences in the multi-year prevalence of HCB consumption among Korean adolescents. Moreover, this might be among the first studies to investigate associations between HCB consumption and behavioral factors using the multi-year KYRBS data. This study revealed that more male participants consumed $\mathrm{HCB}$ than female participants. HCB consumption was related to unhealthy behaviors (e.g., alcohol intake, tobacco use, sweetened beverage consumption, and insufficient sleep) and mental health problems (e.g., considering or attempting suicide). We identified that HCB intake was associated with simultaneous health risk behaviors and problems. Therefore, we need to intervene on HCB consumption and concurrent multiple health risk behaviors and problems together, especially targeting Korean male adolescents.

Overall, the HCB consumption prevalence was higher in boys than in girls (17.2\% vs. $13.1 \%$ ), which aligns with prior research findings [13,21]. In 2017, the HCB consumption prevalence was $26.7 \%$ for boys and $20.9 \%$ for girls. These rates are nearly twice as high as the reported prevalence (12.2\%) in a previous study of Korean adolescents in both boys and girls in 2015 [13]. The present study found a rapid 
Table 2. Characteristics of girls by highly caffeinated beverage consumption, Korea Youth Risk Behavior Web-based Survey 2014-2017

\begin{tabular}{|c|c|c|c|c|c|}
\hline Characteristic & $\begin{array}{c}\text { Total } \\
(n=130,806) \\
(\%)\end{array}$ & $\begin{array}{c}\text { Drinker } \\
(n=17,014) \\
(\%)\end{array}$ & $\begin{array}{c}\text { Nondrinker } \\
(n=113,792) \\
(\%)\end{array}$ & $\begin{array}{l}\text { Effect } \\
\text { size }^{\text {a) }}\end{array}$ & $p$ \\
\hline \multicolumn{6}{|l|}{ School type } \\
\hline Middle school & 46.6 & 45.6 & 46.8 & 0.008 & 0.090 \\
\hline High school & 53.4 & 54.4 & 53.3 & & \\
\hline \multicolumn{6}{|l|}{ Academic achievement } \\
\hline Low & 33.5 & 38.6 & 32.7 & 0.042 & $<0.001$ \\
\hline Middle & 29.4 & 28.0 & 29.6 & & \\
\hline High & 37.1 & 33.4 & 37.7 & & \\
\hline \multicolumn{6}{|l|}{ Household income } \\
\hline Low & 16.5 & 17.9 & 16.3 & 0.025 & $<0.001$ \\
\hline Middle & 49.6 & 46.4 & 50.1 & & \\
\hline High & 33.9 & 35.7 & 33.6 & & \\
\hline \multicolumn{6}{|l|}{ Weekly expenditure } \\
\hline$<50,000 \mathrm{KRW}(<$ USD 44.66) & 86.5 & 82.2 & 87.2 & 0.053 & $<0.001$ \\
\hline 50,000-99,999 KRW (USD 44.66-89.32) & 10.0 & 12.4 & 9.6 & & \\
\hline$\geq 100,000 \mathrm{KRW}(\geq$ USD 89.33) & 3.5 & 5.5 & 3.2 & & \\
\hline \multicolumn{6}{|l|}{ Paternal education } \\
\hline$\leq$ Middle school & 2.7 & 3.2 & 2.7 & 0.012 & 0.004 \\
\hline High school & 35.3 & 34.6 & 35.3 & & \\
\hline$\geq$ College & 62.0 & 62.1 & 62.0 & & \\
\hline \multicolumn{6}{|l|}{ Maternal education } \\
\hline$\leq$ Middle school & 2.5 & 3.0 & 2.5 & 0.018 & $<0.001$ \\
\hline High school & 44.8 & 42.7 & 45.1 & & \\
\hline$\geq$ College & 52.7 & 54.3 & 52.5 & & \\
\hline \multicolumn{6}{|l|}{$\mathrm{BMI}^{\mathrm{b})}$} \\
\hline Underweight & 6.3 & 6.0 & 6.4 & 0.016 & $<0.001$ \\
\hline Normal weight & 78.8 & 77.7 & 78.9 & & \\
\hline Overweight & 8.5 & 9.1 & 8.4 & & \\
\hline Obese & 6.4 & 7.3 & 6.3 & & \\
\hline \multicolumn{6}{|l|}{ Alcohol use } \\
\hline Never & 64.6 & 56.4 & 65.8 & 0.066 & $<0.001$ \\
\hline Ever & 35.4 & 43.6 & 34.2 & & \\
\hline \multicolumn{6}{|l|}{ Tobacco use } \\
\hline Never & 91.6 & 86.9 & 92.2 & 0.064 & $<0.001$ \\
\hline Ever & 8.4 & 13.1 & 7.8 & & \\
\hline \multicolumn{6}{|l|}{ Weekly physical activity for $\geq 60 \mathrm{~min}$} \\
\hline None & 44.6 & 41.5 & 45.1 & 0.024 & $<0.001$ \\
\hline $1-2$ days & 33.9 & 35.8 & 33.7 & & \\
\hline$\geq 3$ days & 21.5 & 22.7 & 21.3 & & \\
\hline \multicolumn{6}{|l|}{ Weekly vigorous exercise for $\geq 20 \mathrm{~min}$} \\
\hline None & 34.1 & 32.1 & 34.4 & 0.016 & $<0.001$ \\
\hline $1-2$ days & 41.5 & 42.8 & 41.4 & & \\
\hline$\geq 3$ days & 24.3 & 25.1 & 24.2 & & \\
\hline \multicolumn{6}{|l|}{ Weekly frequency of soda consumption } \\
\hline 0 times & 29.3 & 17.8 & 31.0 & 0.148 & $<0.001$ \\
\hline $1-2$ times & 48.9 & 45.5 & 49.4 & & \\
\hline$\geq 3$ times & 21.8 & 36.7 & 19.6 & & \\
\hline
\end{tabular}


Table 2. Continued

\begin{tabular}{|c|c|c|c|c|c|}
\hline Characteristic & $\begin{array}{c}\text { Total } \\
(n=130,806) \\
(\%)\end{array}$ & $\begin{array}{c}\text { Drinker } \\
(n=17,014) \\
(\%)\end{array}$ & $\begin{array}{c}\text { Nondrinker } \\
(n=113,792) \\
(\%)\end{array}$ & $\begin{array}{l}\text { Effect } \\
\text { size }\end{array}$ & $p$ \\
\hline \multicolumn{6}{|c|}{ Weekly frequency of sweetened beverage consumption } \\
\hline 0 times & 16.1 & 7.7 & 17.4 & 0.144 & $<0.001$ \\
\hline $1-2$ times & 45.0 & 36.1 & 46.3 & & \\
\hline$\geq 3$ times & 38.9 & 56.3 & 36.3 & & \\
\hline \multicolumn{6}{|c|}{ Meeting sleep duration recommendations (8-10 h) } \\
\hline Not met & 87.3 & 88.1 & 87.1 & 0.010 & 0.004 \\
\hline Met & 12.7 & 11.9 & 12.9 & & \\
\hline \multicolumn{6}{|l|}{ Feeling fatigue relief after sleep } \\
\hline Not enough/not enough at all & 48.2 & 55.6 & 47.1 & 0.059 & $<0.001$ \\
\hline Fair & 31.6 & 28.6 & 32.1 & & \\
\hline Very enough/enough & 20.1 & 15.9 & 20.8 & & \\
\hline \multicolumn{6}{|c|}{ Seriously considered suicide during last $12 \mathrm{mo}$} \\
\hline No & 85.2 & 78.3 & 86.2 & 0.075 & $<0.001$ \\
\hline Yes & 14.8 & 21.8 & 13.8 & & \\
\hline \multicolumn{6}{|l|}{ Suicide attempt during last $12 \mathrm{mo}$} \\
\hline No & 96.9 & 93.8 & 97.3 & 0.067 & $<0.001$ \\
\hline Yes & 3.1 & 6.2 & 2.7 & & \\
\hline
\end{tabular}

Use of weighted data with adjustment for the complex survey design. The percentages may not add to 100 because of rounding errors.

KRW, Korean won; USD, United States dollar; BMI, body mass index.

${ }^{\text {a) }}$ Phi effect sizes were considered negligible if $<0.1$, weak if between 0.1 and $<0.2$, moderate if between 0.2 and $<0.4$, and strong if $\geq 0.4$. ${ }^{\text {b) }}$ Underweight (BMI $<5$ th percentile), normal weight (5th percentile $\leq \mathrm{BMI}<85$ th percentile), overweight (85th percentile $\leq \mathrm{BMI}<95$ th percentile), and obese $(\mathrm{BMI} \geq 95$ th percentile).

(13.8\% to 23.9\%) rise in HCB consumption from 2016 to 2017, despite governmental policies to limit access to HCBs for adolescents [11] in Korea. Although it remains necessary to perform a longitudinal analysis that compares HCB use before and after policy implementation and evaluates the effectiveness of the government policies, the present study indicates that overall, current policies to reduce $\mathrm{HCB}$ consumption of Korean adolescents are not as efficacious as initially anticipated. The government of Korea should consider enforcing tougher policies that would reduce $\mathrm{HCB}$ use among adolescents since HCBs are likely to be even more popular in the adolescent population. Considering the higher rate of HCB consumption in boys than girls, there is an urgent need to develop sex-specific programs to curb HCB use, especially in boys.

For both sexes, HCB drinkers had higher odds of alcohol and tobacco use than HCB nondrinkers. This result is in accord with the previous literature $[19,22]$, which has shown that adolescents mix HCBs with alcohol and that this risky behavior is related to other unhealthy behaviors (e.g., higher alcohol consumption, drunk driving, and unprotected sex). HCB drinkers had higher odds of feeling unrested after sleep and having suicidal thoughts and suicide attempts. Furthermore, more HCB users than nonusers did not meet the recommended sleep duration in boys (78.5\% vs. $75.4 \%$ ), but this trend was not found in girls. However, the magnitude of the association was negligible. This result aligns with prior research, which has found a relationship between $\mathrm{HCB}$ consumption and shorter sleep duration among adolescents [21]. The present study found that HCB use was related to suicidal behavior. Given that suicide remains the leading cause of death among Korean adolescents [23], it is important for middle and high schools in Korea to identify effective strategies to address the early stages of HCB use among students. Additional research is needed to determine causal links between HCB consumption and sleep quality and sleep duration among adolescents.

In both sexes, HCB drinkers had higher odds of (1) being obese, (2) drinking soda at least once a week, and (3) drinking sweetened beverages at least once a week. These findings are consistent with previous evidence that the sugar content and the resulting sweet flavor are associated with $\mathrm{HCB}$ consumption $[24,25]$. Those findings also suggest that for adolescents who consume HCBs, the sugar content and its subsequent impact on weight may mask any weightloss effect expected from the caffeine content [26]. Thus, HCB abuse should be considered a vital determinant of obesity as well as caffeine abuse. Since the transition 


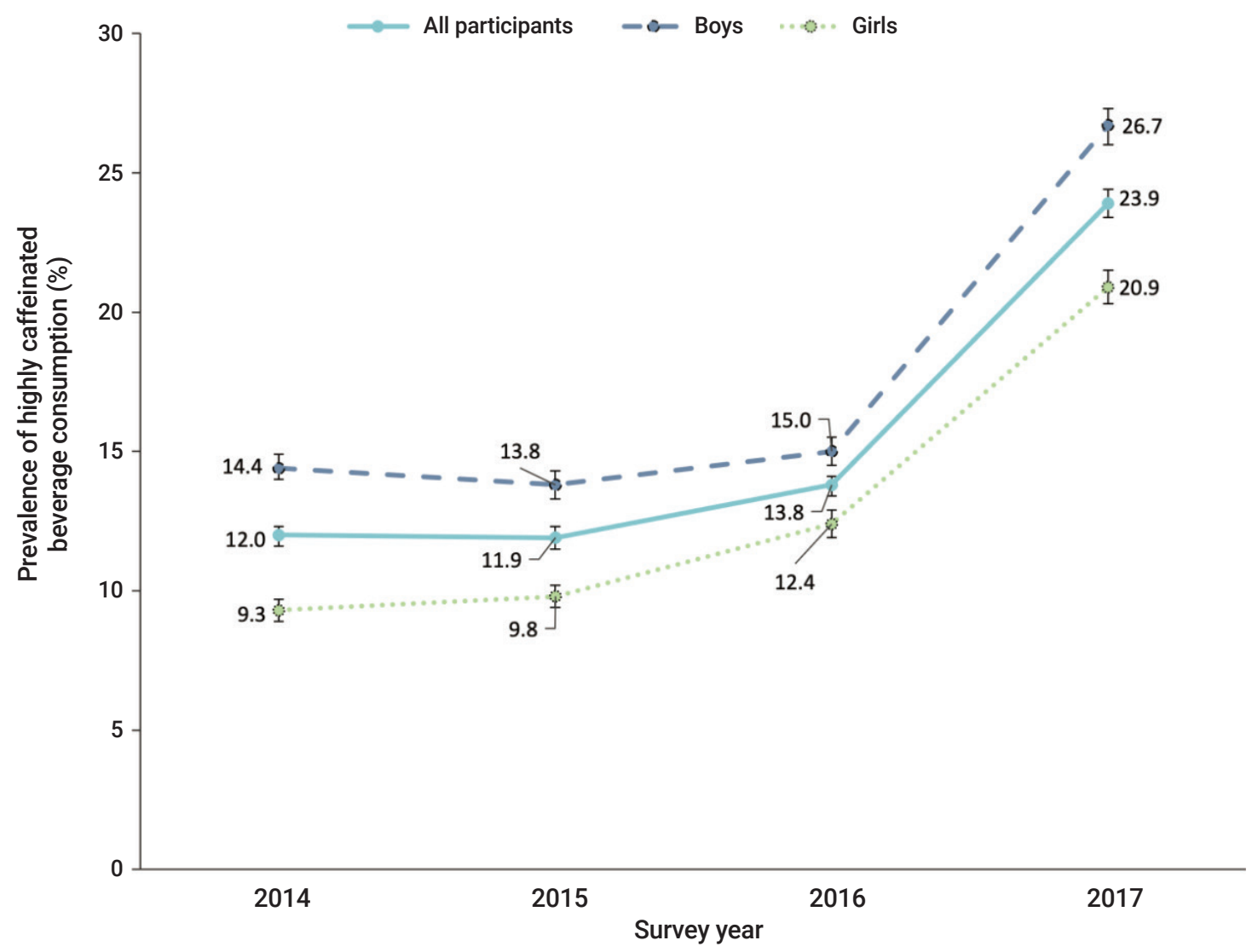

Figure 1. Prevalence (\%) of highly caffeinated drink consumption by survey year among all participants $(n=267,907)$, using weighted data for the complex survey design.

from adolescence to adulthood is a stage of particular risk for obesity and weight gain [22], health professionals in middle and high schools should develop health education programs. These programs should help their students become aware of the health effects of HCB consumption, which may consequently lead to less intake of them.

The adolescents in this study showed some sex differences in the relationship between HCB consumption and vigorous exercise. Among boys, in comparison with nondrinkers, $\mathrm{HCB}$ drinkers had higher odds of reporting $\geq 20$ minutes of vigorous exercise $\geq 3$ days per week. Considering that boys expect higher energy and better athletic performance from caffeine [27], they may believe that HCBs improve their workouts. Consequently, this may result in HCB use for vigorous-intensity exercise. An association between $\mathrm{HCB}$ consumption and vigorous exercise was not found in girls. Prior research has shown that girls were less likely to use caffeine for athletic performance [27]. Given research findings that caffeine may increase blood pressure and the risk of myocardial infarction during exercise [28], the aforementioned finding of the present study highlights the need to develop tailored school-based education programs. These programs should focus on discouraging $\mathrm{HCB}$ consumption and encouraging a healthy diet (e.g., drinking water) during workouts especially in boys.

Another notable finding was that girls with mothers having a high school education had lower odds of $\mathrm{HCB}$ consumption than those with mothers having a middle school education or less. Evidence indicates that the maternal education level is related to health behaviors of their children and that mothers play a vital role in preventing and treating obesity in their children [29]. Research has shown that mothers with lower education levels make more unhealthy foods available at home [29], whereas mothers with higher education levels feed their children nutritious foods and limit their children's access to unhealthy foods [30]. The result of this study indicates the need for health educators in Korea to provide mothers with health education programs that help them become aware of the health consequences of HCB consumption. Future studies should consider the important role that mothers play in reducing $\mathrm{HCB}$ consumption, and more rigorous experimental studies focusing on this topic are needed to establish a causal link between maternal education level and HCB use. 
Table 3. Multiple logistic regression analysis of highly caffeinated beverage consumption, Korea Youth Risk Behavior Web-based Survey 2014-2017

\begin{tabular}{|c|c|c|c|}
\hline Variable & All $(n=267,907)$ & Boy $(n=137,101)$ & $\operatorname{Girl}(n=130,806)$ \\
\hline \multicolumn{4}{|l|}{ Sex } \\
\hline Girl & Reference & - & - \\
\hline Boy & $1.25(1.20-1.31)^{\star \star \star}$ & - & - \\
\hline \multicolumn{4}{|l|}{ Paternal education } \\
\hline$\leq$ Middle school & Reference & Reference & Reference \\
\hline High school & $0.92(0.83-1.02)$ & $0.92(0.80-1.06)$ & $0.91(0.78-1.06)$ \\
\hline$\geq$ College & $0.95(0.85-1.05)$ & $0.96(0.84-1.10)$ & $0.93(0.79-1.09)$ \\
\hline \multicolumn{4}{|l|}{ Maternal education } \\
\hline$\leq$ Middle school & Reference & Reference & Reference \\
\hline High school & $0.88(0.79-0.98)^{*}$ & $0.91(0.79-1.06)$ & $0.84(0.72-0.98)^{*}$ \\
\hline$\geq$ College & $0.99(0.88-1.10)$ & $1.00(0.86-1.16)$ & $0.97(0.83-1.13)$ \\
\hline \multicolumn{4}{|l|}{$\mathrm{BMI}^{\mathrm{a})}$} \\
\hline Underweight & $0.90(0.84-0.96)^{\star *}$ & $0.90(0.82-0.98)^{\star}$ & $0.91(0.82-1.00)$ \\
\hline Normal & Reference & Reference & Reference \\
\hline Overweight & $1.07(1.01-1.13)^{\star}$ & $1.06(0.98-1.14)$ & $1.09(1.00-1.18)^{\star}$ \\
\hline Obese & $1.22(1.15-1.29)^{\star \star \star}$ & $1.21(1.12-1.30)^{\star \star \star}$ & $1.24(1.13-1.37)^{\star \star \star}$ \\
\hline \multicolumn{4}{|l|}{ Alcohol use } \\
\hline Never & Reference & Reference & Reference \\
\hline Ever & $1.17(1.13-1.22)^{\star \star \star}$ & $1.16(1.10-1.22)^{\star \star \star}$ & $1.19(1.13-1.26)^{\star \star \star}$ \\
\hline \multicolumn{4}{|l|}{ Tobacco use } \\
\hline Never & Reference & Reference & Reference \\
\hline Ever & $1.11(1.06-1.16)^{\star \star \star}$ & $1.10(1.04-1.16)^{\star \star}$ & $1.11(1.02-1.21)^{\star}$ \\
\hline \multicolumn{4}{|c|}{ Weekly physical activity for $\geq 60 \mathrm{~min}$} \\
\hline None & Reference & Reference & Reference \\
\hline $1-2$ days & $1.10(1.06-1.15)^{\star \star \star}$ & $1.14(1.07-1.21)^{\star \star \star}$ & $1.08(1.02-1.14)^{\star \star}$ \\
\hline$\geq 3$ days & $1.04(1.00-1.09)$ & $1.06(1.00-1.12)$ & $1.03(0.96-1.11)$ \\
\hline \multicolumn{4}{|c|}{ Weekly vigorous exercise for $\geq 20 \mathrm{~min}$} \\
\hline None & Reference & Reference & Reference \\
\hline $1-2$ days & $1.04(0.99-1.09)$ & $1.05(0.97-1.13)$ & $1.04(0.98-1.10)$ \\
\hline$\geq 3$ days & $1.05(1.00-1.11)$ & $1.08(1.01-1.16)^{\star}$ & $1.02(0.94-1.09)$ \\
\hline \multicolumn{4}{|c|}{ Weekly frequency of soda consumption } \\
\hline 0 times & Reference & Reference & Reference \\
\hline $1-2$ times & $1.41(1.35-1.48)^{\star \star \star}$ & $1.55(1.44-1.67)^{\star \star \star}$ & $1.33(1.25-1.42)^{\star \star \star}$ \\
\hline$\geq 3$ times & $2.32(2.20-2.44)^{\star \star \star}$ & $2.71(2.51-2.92)^{\star \star \star}$ & $1.99(1.85-2.13)^{\star \star \star}$ \\
\hline \multicolumn{4}{|c|}{ Weekly frequency of sweetened beverage consumption } \\
\hline 0 time & Reference & Reference & Reference \\
\hline $1-2$ times & $1.61(1.52-1.71)^{\star \star \star}$ & $1.78(1.63-1.95)^{\star \star \star}$ & $1.45(1.33-1.57)^{\star \star \star}$ \\
\hline$\geq 3$ times & $2.35(2.21-2.49)^{\star \star \star}$ & $2.37(2.17-2.59)^{\star \star \star}$ & $2.33(2.14-2.54)^{\star \star \star}$ \\
\hline \multicolumn{4}{|c|}{ Meeting sleep duration recommendations (8-10 h) } \\
\hline Not met & $1.04(0.99-1.09)$ & $1.06(1.01-1.13)^{\star}$ & $1.01(0.94-1.09)$ \\
\hline Met & Reference & Reference & Reference \\
\hline \multicolumn{4}{|l|}{ Feeling fatigue relief after sleep } \\
\hline Not enough/not enough at all & $1.22(1.17-1.28)^{\star \star \star}$ & $1.18(1.12-1.25)^{\star \star \star}$ & $1.29(1.20-1.38)^{\star \star \star}$ \\
\hline Fair & $1.07(1.02-1.12)^{\star \star}$ & $1.05(0.99-1.11)$ & $1.11(1.03-1.19)^{\star \star}$ \\
\hline Very enough/enough & Reference & Reference & Reference \\
\hline \multicolumn{4}{|c|}{ Seriously considered suicide during last $12 \mathrm{mo}$} \\
\hline No & Reference & Reference & Reference \\
\hline Yes & $1.11(1.05-1.16)^{\star \star \star}$ & $1.08(1.00-1.16)^{\star}$ & $1.13(1.06-1.20)^{\star \star \star}$ \\
\hline
\end{tabular}


Table 3. Continued

\begin{tabular}{llll}
\hline Variable & All $(n=267,907)$ & Boy $(n=137,101)$ & Girl $(n=130,806)$ \\
\hline Suicide attempt during last $12 \mathrm{mo}$ & & & \\
$\quad$ No & Reference & Reference & Reference \\
Yes & $1.44(1.31-1.58) \star \star \star$ & $1.62(1.39-1.87)^{\star \star \star}$ & $1.31(1.16-1.49)^{\star \star \star}$ \\
\hline
\end{tabular}

Data are presented as adjusted odds ratio (95\% confidence interval). Odds ratio adjusted for school year, family level household income, weekly expenditure, and academic achievement. Use of weighted data with adjustment for the complex survey design.

BMI, body mass index.

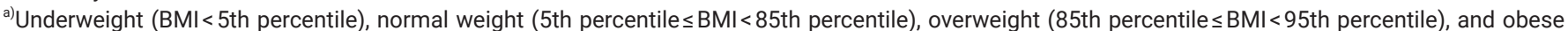
(BMI $\geq 95$ th percentile).

${ }^{\star} p<0.05, * \star p<0.01, * \star * p<0.001$.

This study has limitations. First, although efforts were made to include and control for known confounders, there are unmeasured confounders (e.g., types of HCBs, nutrient content of HCBs, and access to HCBs) that could potentially influence the association between independent variables and HCB consumption. Second, this study used self-reported data. Since adolescents have been shown to under-report their body weight and over-report their height [31], the BMI percentiles computed in this study may have differed slightly from those made using direct anthropometric measurements. In addition, the study findings might have been confounded by unintentional recall bias. Third, this study relied on BMI percentiles to assign weight categories. Although BMI percentiles are commonly used to predict adiposity in children and adolescents, they cannot account for individuals' body composition (e.g., amount of fat mass vs. fat-free mass) or fat distribution (e.g., abdominal vs. nonabdominal fat). Finally, this study was not a longitudinal analysis, despite having used multiple years of data. Therefore, the numbers reported herein reflect correlation, but not necessarily causation. Despite these limitations, this study provides data on the prevalence of HCB consumption and its behavioral correlates among Korean adolescents. This study also found significant growth in HCB consumption between 2016 and 2017, despite the Korean government's efforts to curb adolescents' caffeine abuse. New strategies are needed to effectively curb HCB consumption among the adolescent population. Longitudinal studies are needed to further investigate HCB consumption among Korean adolescents.

\section{Notes}

\section{Ethics Approval}

This study was approved by the Touro University Institutional Review Board (IRB No: PH0219)

\section{Conflicts of Interest}

The authors have no conflicts of interest to declare.

\section{Funding}

None.

\section{Availability of Data}

Data can be made available through the authors.

\section{Authors' Contributions}

Conceptualization: HKK, JS, JL; Data analysis: HKK, JS, SC, JL; Methodology: JS, JL, SC; Validation: all authors; Visualization: HKK, JS, SC, JPC, JL; Writing-original draft: HKK, JS, SC, JL; Writing-review \& editing: JPC, JC, GC.

\section{References}

1. Reissig CJ, Strain EC, Griffiths RR. Caffeinated energy drinks: a growing problem. Drug Alcohol Depend 2009;99:1-10.

2. Wolk BJ, Ganetsky M, Babu KM. Toxicity of energy drinks. Curr Opin Pediatr 2012;24:243-51.

3. Shabir A, Hooton A, Tallis J, et al. The influence of caffeine expectancies on sport, exercise, and cognitive performance. Nutrients 2018;10:1528.

4. Ko G. Energy drink market status and regulatory trend. KHIDI Brief 2014;154:1-8. Korean.

5. Lim H. Survey on safety of energy drink. Consumer safety. Seoul: Korea Consumer Agency; 2013. Korean.

6. Lim HS, Hwang JY, Choi JC, et al. Assessment of caffeine intake in the Korean population. Food Addit Contam Part A Chem Anal Control Expo Risk Assess 2015;32:1786-98.

7. Shin J, Kim SY, Yoon J. Status of coffee intake in South Korea: analysis of 2007-2009 Korea National Health and Nutrition Examination Survey. Korean J Community Living Sci 2016;27:83-93. Korean.

8.HeckmanMA,WeilJ, Gonzalezde MejiaE.Caffeine(1,3,7-trimethylxanthine) in foods:acomprehensivereview on consumption, functionality, safety, andregulatory matters. J Food Sci 2010;75:R77-87.

9. Seifert SM, Schaechter JL, Hershorin ER, et al. Health effects of energy drinks on children, adolescents, and young adults. Pediatrics 2011;127:511-28.

10. Ryu SH. Energy drink consumption status and associated factors among male and female high school students in Deajon area. Korean J Food Nutr 2016;29:899-910. Korean.

11. Korean Ministry of Food and Drug Safety. Health functional food code. Cheongju: Korean Ministry of Food and Drug Safety; 2019.

12. Jin $\mathrm{MJ}$, Yoon $\mathrm{CH}$, Ko $\mathrm{HJ}$, et al. The relationship of caffeine intake with depression, anxiety, stress, and sleep in Korean adolescents. Korean 
J Fam Med 2016;37:111-6.

13. Ra JS, Yun HK, Kim HS, et al. Associated factors on energy drink consumption among Korean high school students. J Korean Soc Sch Health 2017;30:48-58. Korean.

14. Korea Centers for Disease Control and Prevention (KCDC). The Korea youth risk behavior web-based survey user's guide. Cheongju: KCDC; 2019. Korean

15. Kim Y, Kawachi I. School- and individual-level predictors of weight status misperception among Korean adolescents: a national online survey. PLoS One 2016;11:e0154826.

16. Kim JH, Yun S, Hwang SS, et al. The 2017 Korean National Growth Charts for children and adolescents: development, improvement, and prospects. Korean J Pediatr 2018;61:135-49.

17. Hirshkowitz M, Whiton K, Albert SM, et al. National Sleep Foundation's updated sleep duration recommendations: final report. Sleep Health 2015;1:233-43.

18. Bulut B, Beyhun NE, Topbas M, et al. Energy drink use in university students and associated factors. J Community Health 2014;39:1004-11.

19. Larson N, DeWolfe J, Story M, et al. Adolescent consumption of sports and energy drinks: linkages to higher physical activity, unhealthy beverage patterns, cigarette smoking, and screen media use. J Nutr Educ Behav 2014;46:181-7.

20. Larson N, Laska MN, Story M, et al. Sports and energy drink consumption are linked to health-risk behaviours among young adults. Public Health Nutr 2015;18:2794-803.

21. Sampasa-Kanyinga H, Hamilton HA, Chaput JP. Sleep duration and consumption of sugar-sweetened beverages and energy drinks among adolescents. Nutrition 2018;48:77-81.
22. Azagba S, Langille D, Asbridge M. An emerging adolescent health risk: caffeinated energy drink consumption patterns among high school students. Prev Med 2014;62:54-9.

23. Kwak CW, Ickovics JR. Adolescent suicide in South Korea: risk factors and proposed multi-dimensional solution. Asian J Psychiatr 2019;43:150-3.

24. Bunting H, Baggett A, Grigor J. Adolescent and young adult perceptions of caffeinated energy drinks: a qualitative approach. Appetite 2013; 65:132-8.

25. Kim EJ, Cheong HS. Study on perceptions and intake of caffeinecontaining favorite foods by rural and urban middle school students in Kyungnam. Korean J Food Cook Sci 2014;30:650-62. Korean.

26. Williams RD Jr, Housman JM, Odum M, et al. Energy drink use linked to high-sugar beverage intake and BMI among teens. Am J Health Behav 2017;41:259-65.

27. Temple JL, Dewey AM, Briatico LN. Effects of acute caffeine administration on adolescents. Exp Clin Psychopharmacol 2010;18:510-20.

28. Hartley TR, Sung BH, Pincomb GA, et al. Hypertension risk status and effect of caffeine on blood pressure. Hypertension 2000;36:137-41.

29. Feng Y, Ding L, Tang X, et al. Association between maternal education and school-age children weight status: a study from the China Health Nutrition Survey, 2011. Int J Environ Res Public Health 2019;16:2543.

30. Choi HJ, Lee HJ, Jang HB, et al. Effects of maternal education on diet, anemia, and iron deficiency in Korean school-aged children. BMC Public Health 2011;11:870.

31. Bae J, Joung H, Kim JY, et al. Validity of self-reported height, weight, and body mass index of the Korea Youth Risk Behavior Web-based Survey questionnaire. J Prev Med Public Health 2010;43:396-402. 